


\title{
Percepción de los efectos de la pandemia y resiliencia de los microempresarios hidalguenses
}

\author{
Karina Valencia Sandoval ${ }^{1}$, Alejandra Corichi García ${ }^{2}$ y María Dolores Martínez García ${ }^{3}$ \\ ${ }^{1}$ Universidad Autónoma del Estado de Hidalgo, karina_valencia@uaeh.edu.mx Circuito La Concepción Km \\ 2.5, Col. San Juan Tilcuautla, San Agustín Tlaxiaca Hidalgo, México C.P. 42160.5540924273 \\ ${ }^{2}$ Universidad Autónoma del Estado de Hidalgo, corichi@uaeh.edu.mx, Circuito La Concepción Km 2.5, Col. \\ San Juan Tilcuautla, San Agustín Tlaxiaca Hidalgo, México C.P. 4216, (771) 717-2000 ext 410 \\ ${ }^{3}$ Universidad Autónoma del Estado de Hidalgo, maria_martinez1078@uaeh.edu.mx, Circuito La Concepción \\ Km 2.5, Col. San Juan Tilcuautla, San Agustín Tlaxiaca Hidalgo, México C.P. 4216, (771) 717-2000 ext 410
}

Información del articulo revisado por pares

Fecha de aceptación: junio-2021

Fecha de publicación en línea: diciembre-2021

DOI: https://doi.org/10.29105/vtga7.1-95

\section{Resumen}

La crisis de salud originada por el Covid-19 está de la mano de una hecatombe económica. El objetivo es aproximarse a la percepción y resiliencia de los microempresarios hidalguenses ante los efectos de la pandemia del Covid-19. Con la hipótesis de que la continuidad económica de los microempresarios ha sido unilateral y sin apoyo de terceros. Se trata de una investigación de tipo cualitativo y descriptivo basada en el acercamiento a 67 microempresarios de Pachuca, Hidalgo seleccionados con un método de muestreo no probabilístico intencional, con el que se buscaron particularidades semejantes en los sujetos de estudio, en este caso la característica solicitada fue ser dueño de una microempresa. Se aplicaron cuatro preguntas que tienen que ver directamente con el impacto del confinamiento, como causa del Covid-19 en las operaciones de sus negocios. Se empleó el software Atlas ti8 para generar nubes de palabras. Los resultados muestran que no todas las microempresas tuvieron la oportunidad de suspender actividades pese al riesgo epidemiológico. Así mismo, los microempresarios tienen conocimientos generales sobre el Covid-19; se encontró que en su generalidad se sintieron abandonados por los diferentes niveles de gobierno pese a sus estrategias de apoyo económico. Sus comentarios se asocian al desánimo y bajas ventas. El grueso de sus réplicas gira en torno a adaptarse a la nueva normalidad. La percepción de los microempresarios ha sido de desesperanza frente a los
The health crisis caused by Covid-19 is hand in hand with an economic catastrophe. The objective is to approximate the perception and resilience of Hidalgo microentrepreneurs in the face of the effects of the Covid-19 pandemic. With the hypothesis that the economic continuity of the microentrepreneurs has been unilateral and without third party support. This is a qualitative and descriptive research based on the approach to 67 microentrepreneurs from Pachuca, Hidalgo selected with an intentional nonprobabilistic sampling method, with which similar particularities were sought in the study subjects, in this case the requested characteristic It was owning a micro-business. Four questions were applied that have to do directly with the impact of confinement, as a cause of Covid-19 in the operations of their businesses. The Atlas ti8 software was used to generate word clouds. The results show that not all microenterprises had the opportunity to suspend activities despite the epidemiological risk. Likewise, microentrepreneurs have general knowledge about Covid-19; It was found that in general they felt abandoned by the different levels of government despite their economic support strategies. Their comments are associated with discouragement and poor sales. The bulk of its replicas revolves around adapting to the new normal. The perception of microentrepreneurs has been one of hopelessness in the face of the health and economic impacts caused 
impactos de salud y económicos originados por la pandemia; sin embargo, también se encuentra resiliencia y adaptación ante la incertidumbre.

Palabras clave: gobierno, incertidumbre, microempresarios, percepción.

\section{INTRODUCCIÓN}

China se ha convertido en el centro de las miradas desde que a finales de 2019 se detectaron a 27 individuos, asociados a un mercado local, que presentaron características de una neumonía viral a la que, después de diferentes análisis, la Organización Mundial de la Salud (OMS) concluyó de forma oficial se trataba de una enfermedad por el nuevo beta-coronavirus denominado SARS-CoV-2. y oficialmente llamado Covid-19 que por su alta propagación y efectos en la salud pública, se declaró el 11 de marzo de 2020 como pandemia llamando la atención de la comunidad científica alrededor del mundo (Apaza, Seminario y Santa-Cruz, 2020).

El virus SARS-CoV-2 se transmite de manera muy ágil a través de las secreciones respiratorias y, de acuerdo a Maguiña et al., (2020) ocasiona una respuesta anormal de tipo inflamatorio en el sistema respiratorio. Sin embargo, la vulnerabilidad ante el Covid-19 no se refleja únicamente en la morbimortalidad, sino también en sus impactos económicos que a nivel mundial ha causado (Luna-Nemecio, 2020).

Después de una visita de trabajo por Italia, dos individuos fueron confirmados con Covid-19 en febrero de 2020 estando en suelo mexicano y a medida que los casos aumentaron el gobierno ha recomendado el distanciamiento social y el confinamiento para combatir la infección. No obstante, ambas medidas han implicado pausar la economía en búsqueda de la salud pública (Frances, 2020). En el caso mexicano, el Estado publicó mediante Acuerdo emitido en el Diario Oficial de la Federación (DOF) el 23 de marzo de 2020 que "el Consejo de Salubridad General reconoce la epidemia de enfermedad por el virus SARS-CoV2 (Covid-19) en México, como una enfermedad grave de atención prioritaria" (DOF,2021).

$$
\text { Interrumpir varias actividades }
$$

by the pandemic; however, there is also resilience and adaptation to uncertainty..

Keywords: government,

microentrepreneurs, perception.

JEL: M10, I15

económicas ha tenido serios efectos incluso en las actividades consideradas esenciales, de tal suerte que la crisis de salud ha estado de la mano de una hecatombe económica.

Pese a no tener fecha de término, el Gobierno Mexicano ha permitido el regreso gradual a las actividades, sin que esto represente el no contagio, denominándose como "nueva normalidad". García y Martínez (2020) exponen que la economía mexicana ya se encontraba vulnerable a priori a la pandemia por la caída en los precios del petróleo y enfatizan la importancia de las micro y pequeñas empresas al tener el $70 \%$ de los empleos del país.

En este contexto, el objetivo de este trabajo es aproximarse a la percepción y resiliencia de los microempresarios hidalguenses ante los efectos de la pandemia del Covid-19. Con la hipótesis de que la continuidad económica de los microempresarios ha sido unilateral y $\sin$ apoyo de terceros.

\section{MARCO TEÓRICO}

La clasificación de la Mipyme, en términos generales, se deriva del número de personal empleado, las diferencias sectoriales y el monto anual de ventas (Larios-Gomez, 2016) (Tabla 1).

Tabla1. Estratificación de empresas

\begin{tabular}{|c|c|c|c|}
\hline $\begin{array}{l}\text { Clasifica } \\
\text { ción }\end{array}$ & Sector & $\begin{array}{l}\text { Rango } \\
\text { de } \\
\text { número } \\
\text { de } \\
\text { trabajad } \\
\text { ores } \\
\end{array}$ & $\begin{array}{l}\text { Rango } \\
\text { de } \\
\text { ventas } \\
\text { anuales } \\
\text { (mdp) }\end{array}$ \\
\hline $\begin{array}{l}\text { Microem } \\
\text { presa }\end{array}$ & Todas & Hasta 10 & Hasta $\$ 4$ \\
\hline \multirow[t]{2}{*}{$\begin{array}{l}\text { Pequeña } \\
\text { empresa }\end{array}$} & Comercio & $\begin{array}{lll}\text { De } & 11 & \text { a } \\
30 & & \\
\end{array}$ & \multirow{2}{*}{$\begin{array}{l}\mathrm{De} \\
\$ 4.01 \quad \mathrm{a} \\
\$ 100\end{array}$} \\
\hline & $\begin{array}{l}\text { Industria y } \\
\text { servicios }\end{array}$ & $\begin{array}{l}\text { De } 11 \text { a } \\
50\end{array}$ & \\
\hline \multirow[t]{2}{*}{$\begin{array}{l}\text { Mediana } \\
\text { Empresa }\end{array}$} & Comercio & $\begin{array}{l}\text { De } 31 \text { a } \\
100\end{array}$ & \multirow{2}{*}{$\begin{array}{l}\text { De } \\
\$ 100.01 \\
\text { a } \$ 250\end{array}$} \\
\hline & Servicios & De 51 a & \\
\hline
\end{tabular}




\begin{tabular}{|l|l|l|l|}
\hline & & 100 & \\
\cline { 2 - 3 } & Industria & $\begin{array}{l}\text { De 51 a } \\
250\end{array}$ & \\
\hline
\end{tabular}

Fuente: DOF,2009

Las Micro, Pequeñas y Medianas Empresas (Mipymes) son creadas, en su generalidad, por personas emprendedoras, $\mathrm{o}$ que no han tenido la posibilidad de insertarse en el mundo laboral, originando gran cantidad de empleos de manera directa e indirecta en las regiones en las que se establecen. Se ve también a las microempresas como medio de empoderamiento social y realización personal.

Sin embargo, las Mipymes disponen de pocos recursos para su actividad y pese a su alto grado de adaptabilidad participan dentro de mercados de alta competencia, además, existe poca capacidad de gestión por parte de los dueños del negocio tomando decisiones más a base de experiencia que de análisis de información y cuentan con fuerza de trabajo pocas veces capacitada (Rocca et al., 2016).

En México, este tipo de empresas representa el $99.8 \%$ de la totalidad de firmas en el país y significan $72.3 \%$ de los empleos, además es significativo que las micro empresas con menos de 10 empleados representan $97.3 \%$ del total (Vega et al., 2020).

Existen diferentes políticas de apoyo para las Mipymes en México, es así que el número de incubadoras de empresas se ha duplicado pese a la poca innovación de los procesos (Vega et al., 2020).

\subsection{El impacto del Covid-19 en las Mipymes}

Se sabe que varios sistemas productivos se han visto afectados y la parálisis económica se ha acentuado. A nivel internacional el arribo de la pandemia ha significado que al menos 600000 micro y pequeñas empresas tuvieran que cerrar sus instalaciones y en otro tanto los ingresos han disminuido hasta en $88 \%$ (Francisco et al., 2020).

La desaceleración económica ha traído consecuencias a nivel internacional, la Organización Internacional del Trabajo (OIT, citada por Maya-Ambía, 2020) señala que 195 millones de empleos han sido destruidos principalmente en países árabes, Europa y la región Asía-Pacífico, por otra parte, en Estados Unidos se estima que, a principios de 2020, aproximadamente 3.3 millones de empresarios cerraron sus empresas, mientras que en América Latina se estima que la cifra es de 2.7 millones de empresas que representan 8.5 millones de empleos (Montiel, et al. 2021).

En el contexto actual y en medio de la alerta sanitaria los gobiernos de diferentes naciones han adoptado estrategias que permitan disminuir la propagación del virus y que, al tiempo, posibilite la pronta recuperación económica.

La tabla 2 muestra los porcentajes de algunas actividades que se realizaron en el entorno interno y externo de las empresas durante el confinamiento, se observa que las microempresas presentan mayores porcentajes y esto se puede explicar por el número de empresas micro en el país con respecto a las grandes, medianas y pequeñas.

Tabla 2. Actividades durante la pandemia a nivel nacional por tamaño de empresa (\%)

\begin{tabular}{|l|r|r|r|}
\hline \multirow{2}{*}{ Variable } & \multicolumn{3}{|c|}{ Tamaño de empresa (\%) } \\
\cline { 2 - 4 } & Grandes & $\begin{array}{c}\text { Mediana } \\
\text { y } \\
\text { pequeñas }\end{array}$ & Micros \\
\hline $\begin{array}{l}\text { Empresas que } \\
\text { implementaron } \\
\text { medidas sanitarias }\end{array}$ & 0.92 & 6.99 & 92.09 \\
\hline $\begin{array}{l}\text { Promovieron medidas } \\
\text { sanitarias entre } \\
\text { clientes, proveedores } \\
\text { y/o visitantes que } \\
\text { acuden a su empresa }\end{array}$ & 1.05 & 7.57 & 91.38 \\
\hline $\begin{array}{l}\text { Minimizaron las } \\
\text { reuniones presenciales } \\
\text { y propiciaron la } \\
\text { comunidad por medios } \\
\text { virtuales }\end{array}$ & 2.11 & 11.11 & 86.79 \\
\hline $\begin{array}{l}\text { No sé han } \\
\text { instrumentado medidas } \\
\text { sanitarias }\end{array}$ & 0.19 & 2.45 & 97.36 \\
\hline $\begin{array}{l}\text { Solicitar créditos o } \\
\text { financiación de } \\
\text { emergencia }\end{array}$ & 0.74 & 7.99 & 91.27 \\
\hline \begin{tabular}{l} 
Fuente: Elaboración propia con datos de INEGI(b), 2021. \\
\hline
\end{tabular} & & & \\
\hline
\end{tabular}

En México se estima una caída del

Producto Interno Bruto (PIB) de $-8.5 \%$ y 10.5\%; además, Montiel et al., (2021) sostienen que aproximadamente $933 \mathrm{mil}$ personas que fueron despedidas a mediados 
de 2020, como causa de la pandemia, son trabajadores cuyo ingreso oscila entre uno y dos salarios mínimos.

El Gobierno Federal optó por una serie de medidas de carácter económico para menguar el impacto por Covid-19 en las empresas, así puede localizarse apoyo vía internet para hacer ventas por este medio y plataformas que promueven el comercio local; además se otorgaron diferentes créditos para apoyar a micronegocios familiares y pequeñas empresas (Gobierno de México, 2021) (Tabla 3).

Tabla 3. Empresas que recibieron algún tipo de apoyo (\%)

\begin{tabular}{|c|c|c|c|}
\hline \multirow[b]{2}{*}{ Variable } & \multicolumn{3}{|c|}{ Tamaño de la empresa } \\
\hline & $\begin{array}{r}\text { Grande } \\
\mathrm{s}\end{array}$ & $\begin{array}{r}\text { Median } \\
\text { a y } \\
\text { pequeña } \\
\mathrm{s}\end{array}$ & $\begin{array}{r}\text { Micro } \\
\mathrm{S}\end{array}$ \\
\hline $\begin{array}{l}\text { Total de empresas } \\
\text { que recibieron } \\
\text { algún tipo de } \\
\text { apoyo }\end{array}$ & 1.18 & 8.84 & 89.98 \\
\hline $\begin{array}{l}\text { Gobierno } \\
\text { (Federal, estatal } \\
\text { o } \\
\text { municipal/alcal } \\
\text { día }\end{array}$ & 0.90 & 6.95 & 92.15 \\
\hline $\begin{array}{l}\text { Cámaras y } \\
\text { organizaciones } \\
\text { empresariales }\end{array}$ & 13.49 & 74.11 & 12.40 \\
\hline $\begin{array}{l}\text { Asociaciones } \\
\text { sociales }\end{array}$ & 0.83 & 24.40 & 74.77 \\
\hline
\end{tabular}

\subsection{Contexto estatal}

Hidalgo cuenta con una población de 3082 841 individuos, prioritariamente mujeres (51.9\%). El grado promedio de escolaridad es de 9.2 grados, lo que equivale a poco más de la educación básica (INEGI(a), 2021).

De acuerdo al Consejo Nacional de Evaluación de la Política de Desarrollo Social (CONEVAL) el ingreso per cápita de la población tuvo una variación anual negativa (0.7\%) entre 2019 y 2020. Las empresas hidalguenses se centran principalmente actividades referentes al comercio (13.9\%), construcción $(9.5 \%)$ e industria alimentaria
(9\%) (SE, 2016).

Con respecto PIB, Hidalgo se encuentra por debajo de la media nacional y en 2019 representó apenas $1.47 \%$ del total nacional, muy por debajo de las entidades que tienen mayor aporte: Ciudad de México (17.7\%) y Estado de México (8.9\%) (Tabla 4).

Tabla 4. Comparativo respecto al PIB Nacional (base 2013)

\begin{tabular}{|l|l|l|r|}
\hline Año & Nacional & Hidalgo & $\begin{array}{l}\text { Aporta } \\
\text { ción al } \\
\text { PIB } \\
\text { Nacion } \\
\text { al (\%) }\end{array}$ \\
\hline 2015 & $17,292,358$ & 258,695 & 1.5 \\
\hline 2016 & $17,747,239$ & 268,834 & 1.51 \\
\hline 2017 & $\begin{array}{l}18,122, \\
261\end{array}$ & 270,118 & 1.49 \\
\hline 2018 & $18,520,044$ & 277,384 & 1.5 \\
\hline 2019 & $18,509,945$ & 271,360 & 1.47 \\
\hline
\end{tabular}

Fuente: Elaboración propia con datos de INEGI, 2020.

De las 598798 empresas registradas en el Sistema de Información Empresarial Mexicano (SIEM), 3868 pertenecen al estado de Hidalgo y se enfocan principalmente en la construcción $(7,45 \%)$ y en menor medida en el sector educativo particular $(0.49 \%)$. Además, el comercio de diferentes productos es de los principales giros en Hidalgo (Tabla $5)$.

Tabla 5. Actividades prioritarias de las empresas hidalguenses

\begin{tabular}{|l|r|}
\hline \multicolumn{1}{|c|}{ Actividad } & Porcentaje \\
\hline $\begin{array}{l}\text { Construcción de obras de } \\
\text { urbanización }\end{array}$ & 7.45 \\
\hline $\begin{array}{l}\text { Comercio al por menor de otros } \\
\text { alimentos }\end{array}$ & 6.67 \\
\hline $\begin{array}{l}\text { Comercio al por menor de } \\
\text { artículos de papelería }\end{array}$ & 4.32 \\
\hline $\begin{array}{l}\text { Comercio al por menor en } \\
\text { tiendas de abarrotes, } \\
\text { ultramarinos y misceláneas }\end{array}$ & 3.96 \\
\hline $\begin{array}{l}\text { Comercio al por menor de } \\
\text { minisupers }\end{array}$ & 2.71 \\
\hline $\begin{array}{l}\text { Comercio al por menor de ropa } \\
\text { excepto de bebé y lencería }\end{array}$ & 2.43 \\
\hline $\begin{array}{l}\text { Comercio al por menor de } \\
\text { calzado }\end{array}$ & 2.02 \\
\hline $\begin{array}{l}\text { Comercio al por menor de } \\
\text { ferreterías y tlapalerías }\end{array}$ & \\
\hline
\end{tabular}




\begin{tabular}{|c|c|}
\hline $\begin{array}{l}\text { Construcción de carreteras, } \\
\text { puentes y similares }\end{array}$ & 1.55 \\
\hline $\begin{array}{l}\text { Comercio al por menor de } \\
\text { teléfonos y otros aparatos de } \\
\text { comunicación }\end{array}$ & 1.53 \\
\hline $\begin{array}{l}\text { Comercio al por menor de } \\
\text { regalos }\end{array}$ & 1.47 \\
\hline $\begin{array}{l}\text { Comercio al por menor departes } \\
\text { y refacciones nuevas para } \\
\text { automóviles, camionetas y } \\
\text { camiones }\end{array}$ & 1.32 \\
\hline \begin{tabular}{|l|} 
Comercio al por menor de \\
paletas de hielo y helados
\end{tabular} & $1,19 \%$ \\
\hline Comercio al por menor de lentes & 1.09 \\
\hline \begin{tabular}{|l|} 
Comercio al por menor en \\
tiendas departamentales
\end{tabular} & 1.09 \\
\hline $\begin{array}{l}\text { Comercio al por menor de } \\
\text { gasolina y diesel }\end{array}$ & 0.98 \\
\hline \begin{tabular}{|l} 
Comercio al por menor de \\
muebles para el hogar
\end{tabular} & 0.98 \\
\hline \begin{tabular}{|l|} 
Comercio al por menor de \\
artículos y aparatos deportivos
\end{tabular} & 0.93 \\
\hline $\begin{array}{l}\text { Comercio al por menor de } \\
\text { materiales para la construcción } \\
\text { en tiendas de autoservicio } \\
\text { especializado }\end{array}$ & 0.80 \\
\hline $\begin{array}{l}\text { Construcción de obras para el } \\
\text { tratamiento, distribución y } \\
\text { suministro de agua y drenaje } \\
\end{array}$ & 0.80 \\
\hline $\begin{array}{l}\text { Edificación de inmuebles } \\
\text { comerciales y de servicio, } \\
\text { excepto la supervisión }\end{array}$ & 0.78 \\
\hline $\begin{array}{l}\text { Comercio al por menor de } \\
\text { materias primas y artículos para } \\
\text { repostería }\end{array}$ & 0.78 \\
\hline $\begin{array}{l}\text { Comercio al por menor de } \\
\text { automóviles y camionetas } \\
\text { nuevas }\end{array}$ & 0.75 \\
\hline \begin{tabular}{|l|}
$\begin{array}{l}\text { Comercio al por menor de } \\
\text { bisutería y artículos para vestir }\end{array}$ \\
\end{tabular} & 0.75 \\
\hline $\begin{array}{l}\text { Comercio al por mayor de } \\
\text { pintura }\end{array}$ & 0.67 \\
\hline $\begin{array}{l}\text { Comercio al por menor de } \\
\text { artículos de perfumería y } \\
\text { cosméticos }\end{array}$ & 0.65 \\
\hline Casas de empeño & 0.54 \\
\hline $\begin{array}{l}\text { Escuelas del sector privado de } \\
\text { combinan diversos niveles de } \\
\text { educación }\end{array}$ & 0.49 \\
\hline
\end{tabular}

Fuente: Elaboración propia con datos de SIEM, 2021.
Ibarra et al., (2017) indican que en suelo hidalguense, las principales problemáticas de las microempresas son a) la planeación administrativa, b) recursos humanos y c) uso y adaptación a las nuevas tecnologías de información.

Por otra parte, el Gobierno del Estado de Hidalgo emitió, como medidas económicas que beneficiaran a las microempresas ante la pandemia, la prórroga del cobro de financiamientos a las Mypymes que participaron en el programa estatal "Pon tu negocio yo te apoyo", se concedieron créditos con tasa cero y un año para pagarlo, así como el indulto del $50 \%$ al Impuesto Sobre Nómina (CONAMER, 2021).

En Hidalgo el gobierno estatal se sumó a las restricciones sugeridas por el gobierno Federal suspendiendo actividades como antros, bares, balnearios y centros recreativos. Así mismo, implementó medidas restrictivas en cines ( $25 \%$ de su capacidad), gimnasios ( $20 \%$ de su capacidad), salones de belleza y similares (25\% de capacidad), restaurantes y similares $(20 \%$ de mesas ocupadas en espacios cerrado y $30 \%$ en espacio abierto), mercados, tianguis $\mathrm{y}$ supermercados (30\% de su capacidad) plazas comerciales y tiendas departamentales $(25 \%$ de su capacidad) (Gobierno de Hidalgo, 2021).

\section{MÉTODO}

Es una investigación de tipo cualitativo y descriptivo basada en el acercamiento a 67 microempresarios de Pachuca, Hidalgo seleccionados con un método de muestreo no probabilístico intencional dada su sencillez y simplicidad de acercamiento, con el que se buscaron particularidades semejantes en los sujetos de estudio, en este caso la característica solicitada fue ser dueño de una microempresa y que se realiza por selección y determinación del investigador. Este tipo de muestreo es útil cuando se hace la exploración de un fenómeno (Arias-Gómez, VillasísKeeve y Miranda-Novales, 2016). La información se obtuvo entre los meses de enero y marzo de 2021.

A los microempresarios se les 
hicieron cuatro preguntas que tienen que ver directamente con el impacto del confinamiento, como causa del Covid-19 en las operaciones de sus negocios. Con la información obtenida del acercamiento con los empresarios se siguió la metodología empleada por Salgado (2015) que sugiere la aplicación de preguntas abiertas cuyas respuestas narrativas se analizan de acuerdo la recurrencia de las respuestas. Además, se utiliza la propuesta de un enfoque inductivo de Thomas (2006) que menciona "el análisis inductivo se refiere a los enfoques que utilizan principalmente lecturas detalladas de datos crudos para derivar conceptos, temáticas o un modelo a través de interpretaciones hechas a partir de los datos por parte de un evaluador o investigador". Por otra parte, el trabajo forma parte del construccionismo social en que las opiniones recabadas "representa la reconstrucción de la realidad a partir del análisis ontológico de la experiencia" (Robles et al., 2016).

Para lograr el objetivo se empleó el software Atlas ti8 que, de acuerdo con E. Salgado (2015), permite efectuar análisis de tipo cualitativo. Con esta herramienta se generaron "nubes de palabras" que observan de modo gráfico la frecuencia con la que los individuos se refieren a un término específico, en estas nubes el tamaño de la letra es proporcional a su asiduidad en las respuestas de los individuos.

Hernández (2015) señala que para desarrollarlas debe prescindirse de las expresiones de los verbos ser, estar y hacer, así como aquellas que muestran juicios individuales.

De acuerdo con lo anterior, las preguntas planteadas a los empresarios para dar respuesta fueron:

1. ¿Cuál es la noción que tiene sobre el Covid-19?

2. ¿Cómo considera que las medidas tomadas por el gobierno para contrarrestar los efectos del Covid-19 han influido en su negocio?

3. ¿Cómo le afectó la pandemia en las operaciones de su negocio?

4. ¿Cuáles fueron las decisiones al interior de la empresa para dar continuidad a sus actividades productivas?

\section{RESULTADOS}

\subsection{Análisis descriptivo}

Con respecto a las variables que identifican a los microempresarios, la mediana de la edad se ubica en 35 años. Accedieron a responder un mayor porcentaje de mujeres (55.7\%). El nivel de estudios terminado representativo de la muestra corresponde al bachillerato y la licenciatura. $67.2 \%$ vive en zona urbana, mientras que el resto en municipios de zona rural. Con respecto al sector económico al que pertenecen las empresas, éste corresponde al terciario (Tabla 6).

Tabla 6. Descripción de la muestra

\begin{tabular}{clr}
\hline & Variable & $\begin{array}{r}\text { Porcentaje } \\
(\%)\end{array}$ \\
\hline Genero & Hombre & 44.3 \\
Nivel de estudios & 55.7 \\
& Primaria & \\
& Secundaria & 4.9 \\
& Bachillerato & 11.5 \\
& Licenciatura & 37.7 \\
& Postgrado & 37.7 \\
Vive en & 8.2 \\
& Zona rural & 32.8 \\
Zector al que pertenece su negocio & 67.2 \\
& Primario & 4.9 \\
& Secundario & 6.6 \\
Terciario & 88.5 \\
\hline Fuente: elaboración propia
\end{tabular}

En lo que concierne al paro de actividades generada por la pandemia, se observa en la figura 1 que no todas las microempresas tuvieron la oportunidad de suspender actividades y que en su mayoría (82\%) continuaron laborando pese al riesgo epidemiológico.

Figura 1. ¿Suspendieron actividades durante la pandemia?

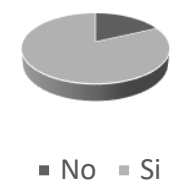

Fuente: (Elaboración propia). 


\subsection{Análisis descriptivo}

El análisis cualitativo de los comentarios emitidos por los microempresarios se realiza a travpés de frecuencia de palabras expresadas en nubes.

\subsection{1. ¿Cuál es la noción que tiene sobre el Covid-19?}

Se percibe al observar la nube generada que los términos recurrentes fueron "virus" y "enfermedad". Los atributos más relacionados al Covid-19 se remiten a los efectos en generales en la población (contagioso, pulmones, muerte) y a su lugar de origen (China, asiático) (Figura 2).

Algunas respuestas de los microempresarios fueron

"Pues que es un virus que todos nos podemos contagiar si no tomamos las medidas necesarias aparte que es un virus mortal"

"Es un virus originario del continente asiático con alta mortalidad a quien lo contraiga, genera afectaciones importantes a nivel pulmonar, su propagación es rápida y mediante los fluidos del infectado"

"Es un virus contagioso que afecta a los pulmones y comenzó en China, extendiéndose por todo el mundo"

Figura 2. Nube de palabras1. ¿Cuál es la noción que tiene sobre el Covid-19?

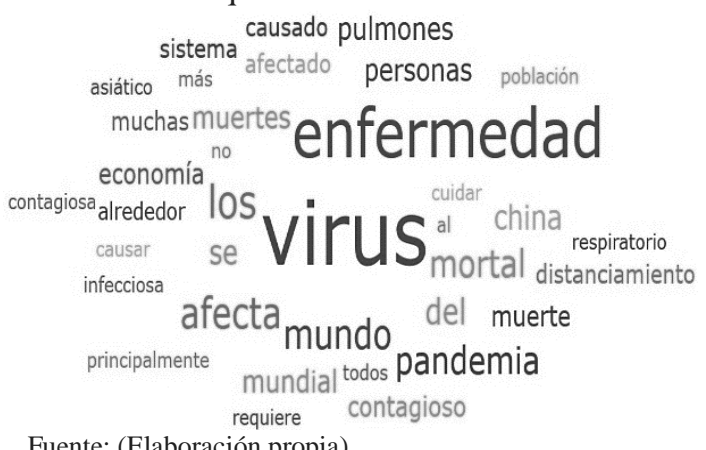

La percepción de riesgo está presente en los resultados obtenidos, de acuerdo a Gómez-Luna et al., (2020) esto puede sumarse a la estrategia de comunicación del gobierno para disminuir los efectos multiplicativos del virus.

4.1.2 ¿Cómo considera que las medidas tomadas por el gobierno para contrarrestar los efectos del Covid-19 han influido en su negocio?

Pese a que la Secretaría de Economía anunció que para 2021 se tiene destinado 1500 millones de pesos que se otorgarán como crédito a la palabra en apoyo a 60000 microempresas y familias que han resentido los impactos de la pandemia (IMSS, 2021), la percepción que los empresarios hidalguenses tienen es de abandono como en sus respuestas se lee:

"Nunca apoyan de ninguna manera jamás he recibido apoyo de ni ninguna manera, ni antes ni durante la pandemia"

"No mucho, mayormente los problemas de estos pequeños negocios pasan desapercibidos"

"En mi caso no he recibido ayuda, dicen que a algunos negocios les dieron créditos, pero a mí no"

Únicamente cuatro empresarios mencionaron tener apoyo por parte de instituciones gubernamentales, la figura 3 permite deducir que la percepción generalizada es que no hubo apoyo por parte del gobierno (Figura 3).

Figura 3. Nube de palabras ¿Cómo considera que las medidas tomadas por el gobierno para contrarrestar los efectos del

Covid -19 han influido en su negocio?



Fuente: (Elaboración propia).

Por experiencia internacional, investigadores como Camberos y Bracamontes (2015) señalan que las crisis incrementan las brechas de desigualdad entre la población, mencionan la premura de reformas económicas.

Por su parte Montiel et al., (2021) sostienen que el apoyo del Estado es decisivo para las empresas en tiempos de dificultad, para poder continuar con sus actividades económicas y productivas.

\subsection{3 ¿Cómo le afectó la pandemia en las operaciones de su negocio?}


Muchos de los participantes hicieron referencia a las bajas ventas derivados de la eventualidad. Sus comentarios se asocian al desánimo y pesimismo originado por la caída de sus transacciones (Figura 4).

"Nuestro negocio requiere de visitas de campo a nuestros clientes, promoción directa con asociaciones y empresas, asimismo, al no contar con los recursos necesarios para adquirir plataformas digitales que nos permitan impartir cursos a distancia, no hemos podido realizar las capacitaciones, ni las visitas de promoción para atraer más clientes"

"Disminución de ventas, aumento del precio de productos por mayoreo, desabastecimiento de productos de primera necesidad"

"Desafortunadamente como estamos brindando asesoría y las personas no fácilmente admiten a personas extrañas, pues prefieren mantener la distancia con nosotros antes de que les pueda pasar algo"

Figura 4. Nube de palabras ¿Cómo le afectó la pandemia en las operaciones de su negocio?

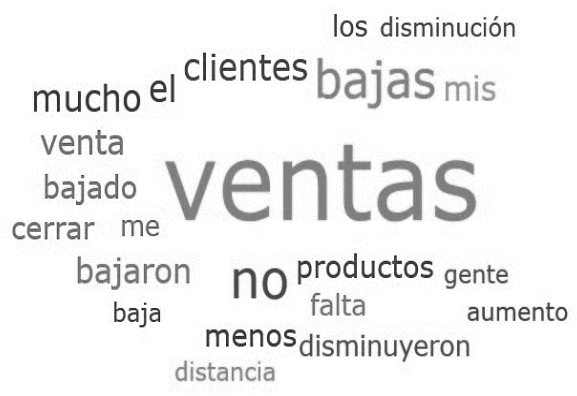

Fuente: (Elaboración propia).

\subsection{4 ¿Cuáles fueron las decisiones al interior de la empresa para dar continuidad a sus actividades productivas?}

Una imagen de adaptación y resiliencia es la última respuesta que comparten los empresarios. El grueso de sus réplicas a la pregunta hecha gira en torno a adaptarse a la nueva normalidad mediante el uso de implementos como el cubrebocas, exigido tanto a sus empleados como a sus clientes con el fin de seguir siendo productivos al tiempo de preservar su salud.

Además, se deduce que varios negocios tuvieron que implementar la entrega a domicilio y las compras y contacto con los clientes en línea a través de redes sociales principalmente, es decir, los microempresarios que no necesariamente se dedican a cuestiones tecnológicas se vieron obligados a reinventarse y aprender del uso de la Internet como medio de comercialización (Figura 5).

"Solo cuando me cerraron completamente tenía que entregar los pedidos a domicilio sin costo de envío y eso hizo que disminuyan mis ganancias, ya que gasto más, aparte de insumos también tenía que considerar el empaque y también gasolina que corrían por mi cuenta"

"Ahora es más tardado atender a las personas por el uso de gel, los tapetes sanitizantes, desinfección del dinero y la limpieza más profunda"

"Tener un control de salud para cada empleado, así como seguir las recomendaciones (uso de careta, cubrebocas, guantes y gel antibacterial)"

Figura 5. Nube de palabras ¿Cuáles fueron las decisiones al interior de la empresa para dar continuidad a sus actividades productivas?

$$
\begin{aligned}
& \begin{array}{c}
\text { compras son negocio normal } \\
\text { menospedidos }{ }^{\text {nimpieza personal }} \\
\text { normalidad clientes } \\
\text { cambió mel medidas }
\end{array} \\
& \text { guantesventas Cubrebocas línea momento }
\end{aligned}
$$

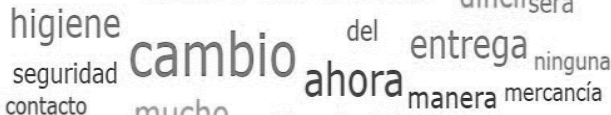

$$
\begin{aligned}
& \begin{array}{c}
\text { contacto mucho antibacterial } \\
\text { igual insumos } \\
\text { disminución distancia }
\end{array} \\
& \text { domicilio empleadoshorarios }
\end{aligned}
$$

Fuente: (Elaboración propia).

Lo anterior coincide con el trabajo de Isler (2020) quien señala que la inocuidad debe formar parte de las transacciones comerciales y síntoma de la responsabilidad social empresarial.

Por su parte, Sumba-Bustamante (2020) señala que la comercialización tradicional se ha visto rebasada por la digitalización y el 
comercio electrónico como medio para fortalecer las relaciones comerciales durante el aislamiento.

\section{CONCLUSIONES}

A causa de la globalización y los intercambios comerciales internacionales, las empresas se han visto en la necesidad de afrontar incertidumbre y desarrollar nuevas estrategias que les permitan superar la adversidad causada por la intempestiva aparición y diseminación del Covid-19.

Los resultados muestran que de manera general hay pesimismo y desesperanza entre los empresarios que han visto disminuidas sus ventas y no encuentran oportunidades en medio de la pandemia.

De forma similar, los propietarios de las empresas dicen sentirse abandonados por las instituciones gubernamentales, pese a que se ha implementado una serie de apoyos, pero de los que no se ha tenido conocimiento.

El gobierno debe poner cuidado en su comunicación con los microempresarios, pese a la existencia de apoyos, la generalidad se siente indefenso ante los eventos generados por la pandemia. La gestión adecuada de apoyo económico y los créditos pueden significar la sobrevivencia de las micro empresas y preservación de empleos, sobre todo, entre la comunidad más vulnerable.

Además de ocupar el equipo de prevención necesario y emplear protocolos de distanciamiento, cada empresa, de acuerdo a su entorno y necesidades, debe generar una serie de estrategias que le permitan su continuidad y competitividad. Sin embargo, en este sentido la responsabilidad debe ser compartida entre gobierno, empresario, empleados, consumidores y sociedad.

En términos generales la percepción de los microempresarios ha sido de desesperanza frente a los impactos de salud y económicos originados por la pandemia; sin embargo, también se encuentra resiliencia y adaptación ante la incertidumbre.

Finalmente, se recomienda implementar mayor acercamiento GobiernoMicroempresarios, además de una campaña no sólo de internet que permita dar a conocer las actividades y apoyo que el Estado destina a las microempresas. 


\section{REFERENCIAS}

Apaza, C., Seminario, R. S., Santa-Cruz, J. E. (2020). Factores psicosociales durante el confinamiento por el Covid-19 - Perú. Revista Venezolana de Gerencia, 25(90), 402-413. https://doi.org/10.37960/rvg.v25i90.32385

Arias-Gómez, J., Villasís-Keever, M. A. y Miranda Novales, M. G. (2016). El protocolo de investigación III: la población de estudio. Revista Alergia México, 63(2), 201-206.

Camberos, M. y Bracamontes, J. (2015). Las crisis económicas y sus efectos en el mercado de trabajo, en la desigualdad y en la pobreza de México. Contaduría y Administración, 60(2), 219-249.

Comisión Nacional de Mejora Regulatoria (CONAMER). (2021). Medidas económicas ante la pandemia COVID-19. Recuperado de https://conamer.gob.mx/respuestas-regulatoriascovid-19/MedidasEconomicasLNPP

Diario Oficial de la Federación de México (DOF). (2009). ACUERDO por el que se establece la estratificación de las micro, pequeñas y medianas empresas. México. Recuperado de https://www.economia.gob.mx/files/marco_normativo/A539.pdf

Diario Oficial de la Federación de México (DOF). (2021). LINEAMIENTOS para la Operación del Programa de Apoyo Financiero a Microempresas Familiares 2021. México. Recuperado de https://www.dof.gob.mx/nota detalle.php?codigo $=5611049 \&$ fecha=08/02/2021

Frances, S. (2020). El COVID-19 y la salud mental: ¿cuáles son las consecuencias? Psicología Iberoamericana, 28(1).

Francisco, D., Maciel, F., Janissek, R., Carneiro, A., Callegaro, D., Quadrado, L., Witt Haddad, W. B., Simone, C., Müller, F.,Soares, M. y Rhoden, M. (2020). An engaged university: rescuing smes during the Covid-19 crisis. Forum. 60(6), 437-450. http://dx.doi.org/10.1590/S0034-759020200607

García, A. M. y Martínez, P. (2020). ¿Cuál es el camino después de la pandemia por COVID-19?. En C. Medel, A. Rodríguez, G. Jiménez y R. Rojas, México ante el COVID-19: acciones y retos (pp. 27-40). México: Universidad Autónoma Metropolitana.

Gobierno de Hidalgo (2021). Zona de riesgo epidemiológico Hidalgo. Recuperado de https://coronavirus.hidalgo.gob.mx/

Gobierno de México (2021). COVID-19 Medidas Económicas. Recuperado de https://www.gob.mx/covid19medidaseconomicas

Gomez-Luna, L. M., Guasch-Hechavarría, F., García-González, A., Muñoz-Padilla, A., MoyaGomez, A.E., y Savón-Vaciano, Y. (2020). Un análisis de la percepción del riesgo ante la Covid-19. Ciencia en su PC, 1(2),1-24.

Hernández, C. (2015). Nuevos recursos para la investigación cualitativa: Software gratuito y herramientas colaborativas. Opción, 31(5), 453-471.

Ibarra, M. A., González, A. A. y Demuner, M. R.. (2017). Competitividad empresarial de las pequeñas y medianas empresas manufactureras de Baja California. Estudios fronterizos, 18(35), 107-130. https://doi.org/10.21670/ref.2017.35.a06

Instituto Mexicano del Seguro Social (IMSS). (2021). La Secretaría de Economía anuncia un nuevo paquete de 60,000 apoyos a micronegocios en 2021 con el Programa de Apoyo Financiero a Microempresas Familiares, conocidos como Crédito a la Palabra. Recuperado de http://www.imss.gob.mx/prensa/archivo/202101/CCO06

Instituto Nacional de Estadística y Geografía (INEGI(a)). (2021). Información por entidad. Recuperado de http://cuentame.inegi.org.mx/monografias/informacion/hgo/poblacion/educacion.aspx?te ma $=$ me\&e $=13$

Instituto Nacional de Estadística y Geografía (INEGI (b)). (2021). Encuesta sobre el Impacto Económico Generado por COVID-19 en las Empresas (ECOVID-IE) 2020. Recuperado de https://www.inegi.org.mx/programas/ecovidie/2020/\#Tabulados

Instituto Nacional de Estadística y Geografía (INEGI) . (2020). Producto Interno Bruto por Entidad 
Federativa. Año $2013 . \quad$ base Recuperado de https://www.inegi.org.mx/app/tabulados/default.aspx?pr=17\&vr=6\&in=2\&tp=20\&wr=1 $\& \mathrm{cno}=2$

Isler, E. (2020). La inocuidad: principio informante y de adecuación de deberes preventivos y buenas prácticas en la atención remota y presencial del consumidor durante el contexto de la pandemia de COVID-19. Derecho PUCP, (85), 203-244. https://doi.org/10.18800/derechopucp.202002.007

Larios-Gomez, E. (2016). La gestión de la competitividad en la MIPYME mexicana: diagnóstico empírico desde la gestión del conocimiento. Revista de Administração da Unimep, 14(2), 177-209.

Luna-Nemecio, J. (2020). Determinaciones socioambientales del COVID-19 y vulnerabilidad económica, espacial y sanitario-institucional. Revista De Ciencias Sociales, 26(2), 21-26. https://doi.org/10.31876/rcs.v26i2.32419

Maguiña, C., Gastelo, R. y Tequen, A. (2020). El nuevo Coronavirus y la pandemia del Covid-19. Revista Médica Herediana, 31(2), 125-131. https://dx.doi.org/10.20453/rmh.v31i2.3776

Maya-Ambía, C.J. (2020). Revisión de la discusión actual sobre la Covid-19 en el ámbito del pensamiento social. El trimestre económico, 87(348), 1233-1258. Epub 05 de marzo de 2021.https://doi.org/10.20430/ete.v87i348.1166

Montiel, O., Flores, A., Ávila, E. y Sierra M, S. (2021). "Tengo que sobrevivir": relato de vida de tres jóvenes micro emprendedores bajo COVID-19. Telos: revista de Estudios Interdisciplinarios en Ciencias Sociales, 23 (1), 67-84.

Robles, C., Martínez, E., Alviter, E. E. y Ortega, A. O. (2016). Percepción de la cultura de la calidad en propietarios de microempresas familiares del sector servicios. Acta universitaria, 26(2), 77-92. https://doi.org/10.15174/au.2015.843

Rocca, E., García, D., Duréndez, A. (2016). Factores determinantes del éxito competitivo en la mipyme: un estudio empírico en empresas peruanas. Contabilidad y Negocios, 11(22),5268.

Salgado, R. (2015). Agricultura sustentable y sus posibilidades en relación con consumidores urbanos. Estudios sociales (Hermosillo, Son.), 23(45), 113-140.

Salgado, E. (2015). Diálogo y aprendizaje percibido en estudiantes de modalidad virtual: abordaje cualitativo en un programa universitario en Costa Rica. RIED. Revista Iberoamericana de Educación a Distancia, 18(1),191-211.

Secretaría de Economía (SE). (2016). Información Económica y Estatal. Hidalgo. Recuperado de https://www.gob.mx/cms/uploads/attachment/file/175903/hidalgo_2016_1116.pdf

Sistema de Información Empresarial Mexicano (SIEM). (2021). Consulta de establecimientos. Recuperado de https://siem.economia.gob.mx/ui/pubconsultaestablecimientos

Sumba-Bustamante , R. Y., Almendariz-Gonzalez, S. M., Baque-Chancay , C. L. y Aliatis-Bravo, V. G. (2020). Emprendimientos en tiempo de covid-19: De lo tradicional al comercio electrónico. Revista Científica FIPCAEC, 5(4), 137-164. https://doi.org/10.23857/fipcaec.v5i4.300

Thomas, D. R. (2006). A general inductive approach for analyzing qualitative evaluation data. American Journal of Evaluation, 27(2), 237-246.

Vega, J. E., Bautista, M. C. y Martínez, M. C. (2020). Orientación emprendedora en la innovación de las pequeñas y medianas empresas en México. Revista de Ciencias Sociales, 26(4), 97 114. https://doi.org/10.31876/rcs.v26i4.34651 